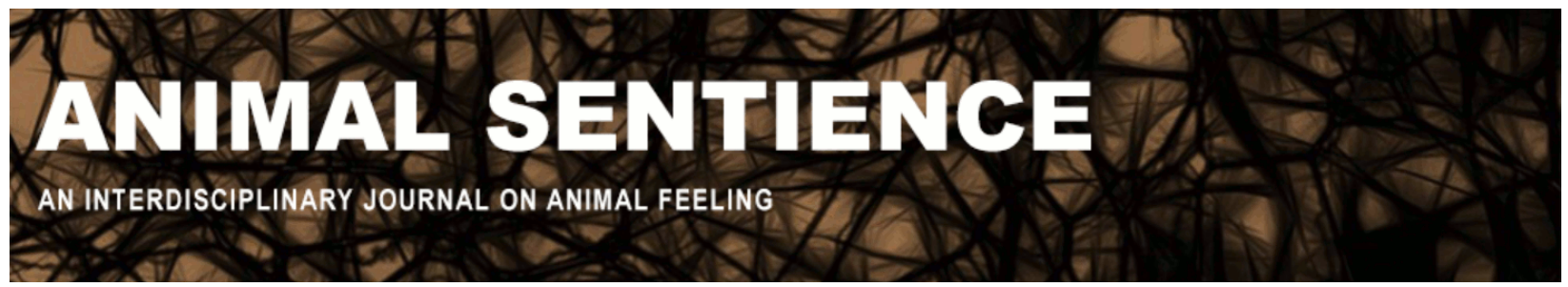

Rollin, Bernard (2017) Raising consciousness about chicken consciousness. Animal Sentience 17(2)

DOI: $10.51291 / 2377-7478.1215$

Date of submission: 2017-10-08

Date of acceptance: 2017-10-12

(c) 


\title{
Raising consciousness about chicken consciousness
}

\author{
Commentary on Marino on Thinking Chickens
}

\author{
Bernard Rollin \\ Department of Philosophy \\ Colorado State University
}

\begin{abstract}
The topics explored by Marino are definitive, and should work well to lay to rest forever the widespread belief that chickens have no personality, are unintelligent, or in any other way lack a mental life.
\end{abstract}

\begin{abstract}
Bernard Rollin is Distinguished Professor of Philosophy, Animal Sciences and Biomedical Sciences, at Colorado State University. One of the leading scholars in animal rights and animal consciousness, he has lectured worldwide. http://philosophy.colostate.edu/people/brollin/
\end{abstract}

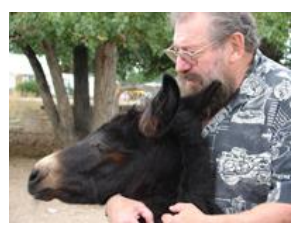

Barely a month ago, I had the distinct pleasure of commenting on another paper by Lori Marino and Kristin Allen entitled "The Psychology of Cows," shortly to appear in Animal Behavior and Cognition. In my commentary, I pointed out how delighted I was to find a paper that is everything one could want in a discussion of animal mind. Not only was the paper scientifically up-to-date and exhaustive: it was solidly grounded in common sense and common decency and discussed forthrightly the ethical and animal welfare implications of the science recounted - something unfortunately quite rare in scientific papers on the subject.

In my 1989 book, The Unheeded Cry (Rollins 1989), I traced both conceptually and historically how, in the eyes (as it were) of the scientific community, "the animals lost their minds" as a legitimate object of study in science. Whereas Darwin had unequivocally taken it for granted that if morphological and physiological traits in animals were phylogenetically continuous with those of humans, so too were psychological and mental traits, the subsequent unfortunate ascendance of behaviorism and positivism ended this biological ecumenism. By the mid- $20^{\text {th }}$ century, one could find virtually no psychologists or ethologists who were willing, in their scientific moments, to speak of animal subjective experiences (Rollin \& Rollin 2014). It was not until 2012 that the scientific community in a consensus conference recognized that animals have thoughts and feelings (Cambridge Declaration on Consciousness, Low et al. 2012)!

The classic volume, Instinctive Behavior, edited by Claire Schiller (1957), chronicles the first interactions of Anglo-American behaviorists with European ethologists of the school of Lorenz and Tinbergen. Though the two schools agreed about little else, they were of one mind in denying consciousness or its knowability in animals. And since an additional ideological component of established science denies the relevance of ethics to science, there was no moral pressure to advance discussions of animal mind. 
Not only did ignoring consciousness lead to moral outrages, such as the failure to utilize analgesia for animals deployed in painful experiments until US federal law passed in 1985 mandated such control of pain and distress, it also led to logical absurdities. To cite two examples, the same research community that denied the reality of animal pain tested all human analgesics on animals (Rollin 1989). Second, although the psychiatric and psychological communities also denied animal mind, when funding became available to do so they were perfectly willing to develop animal models of mental illness, despite the fact that these diseases have inescapable subjective psychological dimensions (Rollin \& Rollin 2014).

In George Orwell's classic work, Animal Farm, one finds the statement "all animals are equal, but some animals are more equal than others." This prescient remark also captures the prevailing view about animal welfare as social concern for animals gradually began to grow across the past 40 or 50 years. The first piece of federal legislation showing concern for animals was the Animal Welfare Act, passed in 1966. This law was really directed at allaying the fear of pet owners that their animals would be kidnapped and sold to research laboratories. (This fear was far from groundless. One of my friends, a veterinary school Dean, showed me a photograph of a sign posted in the neighborhood of Harvard enjoining boys to bring dogs to the Harvard Medical School at a certain time, "no questions asked.") More important for our discussion is the fact that the vast majority of animals used for research - over $90 \%$ - were totally excluded from the Animal Welfare Act. These excluded animals included, among others, rats and mice and birds, including chickens.

The same tendency to favor certain species and ignore others is manifest In the 1957 Humane Slaughter Act, which again does not cover poultry, even though we slaughter more than 9 billion birds a year for food. When public concern about intensive confinement agriculture began to emerge in the US, this concern was primarily directed toward mammals - cows, calves raised for veal, and pigs. It was only when this movement continued to grow that the public began to focus on poultry. The way in which egg-laying hens are kept in battery cages is arguably one of the worst, if not the worst, of many inhumane methods used in modern agriculture. Traditionally, $95 \%$ of egg-laying hens were maintained in small wire cages, with as many as six to a cage. Each animal therefore had less space (67-86 square inches is the official recommendation of United Egg Producers) than that occupied by a sheet of typing paper, and in common situations which I have observed, chickens live on top of other chickens.

Broiler chickens - i.e., animals raised for meat - who 50 years ago took 42 weeks to reach market weight, now do so in seven weeks. Their legs do not develop commensurately, and by the time they go to market, their ability to stand is seriously compromised. I recall in the $1980 \mathrm{~s}$, when I began to work on farm animal welfare issues, some normally intelligent citizens asking me if chickens were animals. And some of my PhD colleagues from Columbia University informed me with pride that for reasons of animal welfare, they purchased Perdue chickens, a company which for 15 years ran ads showing chickens happily pecking in a barnyard with other farm animals there, with the voiceover asserting that "at Perdue we raise happy chickens." Needless to say, this is blatantly false.

Because the Humane Slaughter Act does not cover chickens, slaughter practices are horrendous. While serving on the Pew Commission (2008), the first group to do a detailed study of industrial confinement agriculture, we visited a chicken slaughterhouse. The animals were hung by their feet, heads down, on a conveyor belt. As they approached the killing machine, robotic 
paddles automatically fitted themselves to their heads, and an electric shock theoretically designed to stun them into insensibility was delivered. The animals were then mechanically eviscerated and dumped into scalding water. The stunning failed approximately two thirds of the time, and is now a major issue in society, with people demanding more effective methods.

Happily, as members of society have grown increasingly aware of how animal products are raised, societal concern for the treatment of poultry has expanded exponentially. Many food and restaurant companies have demanded an end to battery cages, and "free-range egg production" is a growth industry in the US, Europe, Australia and New Zealand. Awareness of many of the atrocities detailed above, including slaughter, have reached the social mind, and people are willing to spend more money in support of a decent life for chickens.

I fully agree with Marino's claim that societal apathy regarding chickens is partially a function of commodification of these animals. Furthermore, whereas most of us have had encounters with dogs, cats, and horses, relatively few of us have ever seen a live chicken, let alone interacted with one. I confess to personally having had a similar cavalier attitude about chickens until I acquired a flock of them when we purchased a rural property. It did not take me long to learn that these animals would get to know you, bond with you, greet you and show many signs of affection and attention. In the face of all this, I soon grew very attached to them, particularly one little red hen. Although we kept the chickens in a fairly tall fenced enclosure at night to protect them from predation, coyotes managed to get into the enclosure and killed a number of them, including my red hen. I grieve for her, and still feel, almost 40 years later, a strong measure of regret that I failed to protect her.

In fact, anyone who has kept chickens around the house and spends time with them will bond with them and detect in them many of the traits that one finds in other companion animals. What Lori Marino has done in this excellent paper is to provide a solid scientific basis for the claims that those who live with chickens learn from interacting with them. In other words, instead of what one all too often finds, this paper uses empirical data to support common sense and common decency, not to oppose it.

The topics explored by Marino $(2017 a, b)$ are definitive, and should work well to lay to rest forever the widespread belief that chickens have no personality, are unintelligent, or in any other way lack a mental life. She exhaustively explores the studies on cognition in chickens, most of which provide strong individual evidence of "thinking chickens," but collectively they represent a virtually indubitable case. The mental modalities studied include visual cognition and spatial orientation; recognition of partly and fully occluded objects; numerical abilities; time perception; anticipation of the future; episodic memory; self-control (i.e., trading immediate gratification for future benefit); the ability to reason and utilize logical inferences (the denial of which is a key historical reason for withholding mind from animals, for example by Immanuel Kant and a host of other rationalist philosophers); self-awareness; communication and referential communication; social complexity; discriminating among individuals in a social group; taking the perspectives of others; social learning; the presence of both negative and positive emotions, including fear and emotionally colored anticipation; empathy; and personality. 
Regarding personality, Marino (2017b) remarks:

"the concept of personality is critically important for a complete understand[ing] of animals (including humans) as individuals. Instead of viewing other animals as one-dimensional, interchangeable units within a species, recognition of personality in other animals allows us to accurately see them as complex individuals with multi-dimensional characteristics."

Marino thinks with utmost clarity and carries this clarity into her writing. This excellent paper is highly readable and indeed a pleasure to read. Her moral commitment is made strikingly evident in the last paragraph:

"These findings come with a clear recommendation to continue our exploration of chickens' ethological complexity within noninvasive, non-harmful, and more naturalistic contexts. A shift in how we ask questions about chicken psychology and behavior will, undoubtedly, lead to even more accurate and richer data and a more authentic understanding of who they really are."

\section{References}

Low, P., Panksepp, J., Reiss, D., Edelman, D., Van Swinderen, B., \& Koch, C. (2012) The Cambridge declaration on consciousness. In: Francis Crick Memorial Conference, Cambridge, England.

Marino, L. (2017a) The inconvenient truth about thinking chickens. Animal Sentience 17(1).

Marino, L. (2017b) Thinking chickens: A literature review of cognition, emotion, and behavior in the domestic chicken. Animal Cognition, 20(2): 127-141.

Marino, L., \& Allen, K. (forthcoming) The psychology of cows. Animal Behavior and Cognition.

Pew Commission. (2008) Putting meat on the table: Industrial farm animal production in America. Baltimore, MD: Johns Hopkins Bloomberg School of Public Health.

Rollin, B. (1989) The Unheeded Cry: Animal Consciousness, Animal Pain and Science. Oxford: Oxford University Press.

Rollin, M.D.H., \& Rollin, B.E. (2014) Crazy like a fox: validity and ethics of animal models of human psychiatric disease. Cambridge Quarterly of Healthcare Ethics, 23: 140-151.

Schiller, C. (Ed.). (1957) Instinctive Behavior. New York: International Universities Press. 